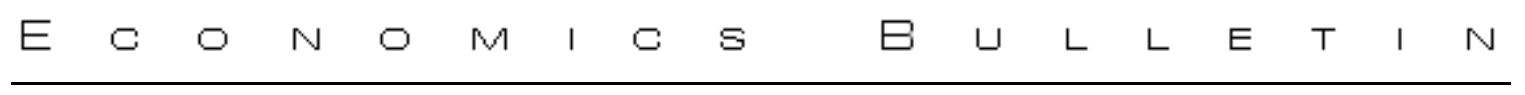

\title{
Revisiting the decline in the exchange rate pass-through: further evidence from developing countries
}

\author{
Karim BARHOUMI \\ GREQAM, Université de la Méditerranée, France and \\ Economics Department of Macquarie University, \\ Australia
}

\author{
Jamel JOUINI \\ F.S.E.G.N. and L.E.G.I., Université 7 Novembre de \\ Carthage, Tunisie and GREQAM, Université de la \\ Méditerranée, France
}

\begin{abstract}
In this paper, we revisit the Taylor (2000) proposition for some developing countries in order to examine the decline in their pass-through coefficients, and to find possible explanations for this. Our work is motivated by the fact that during the 1990s, some developing countries shifted their monetary policy in order to reduce the inflation. We adopt a methodology based on structural break and cointegration approaches proposed by Bai and Perron (1998), and Gregory and Hansen (1996), respectively. These techniques allow identifying the inflation decline and adopting a long-run approach which is ignored in some empirical works related to the pass-through.
\end{abstract}

We are grateful to Mohamed BOUTAHAR, Jocelyn HORNE, Roselyne JOYEUX, Stephane MAHUTEAU and Anne PEGUIN-FEISSOLLE for helpful comments and suggestions. The authors also thank the associate editor Professor David Harvey and the anonymous referee for their constructive criticism which improved the paper. All views expressed in the paper are those of the authors and do not necessarily reflect those of the Bank of France.

Citation: BARHOUMI, Karim and Jamel JOUINI, (2008) "Revisiting the decline in the exchange rate pass-through: further evidence from developing countries." Economics Bulletin, Vol. 3, No. 20 pp. 1-10

Submitted: November 30, 2007. Accepted: April 8, 2008.

URL: http://economicsbulletin.vanderbilt.edu/2008/volume3/EB-07C20152A.pdf 


\section{Introduction}

Recently, there has been a growing interest in examining the relationship of the exchange rate pass-through with monetary policy behavior and inflation environment. We can divide these different works in two categories. The first one is based on finding significant subsample dummy variables, when these are applied to the coefficient on the exchange rate in an univariate pass-through equation. In this context, Gagnon and Ihrig (2001) study the link between consumer prices and monetary policy in some industrialized countries, and test whether the pass-through declines in each country following a change in the inflation regime. Devereux and Yetman (2001) study the link between exchange rate pass-through and monetary policy in the context of a Dynamic General Equilibrium (DGE) model. In their theoretical model, pass-through is determined by the frequency of prices changes of importing firms (this frequency is a function of the monetary policy regime). The second category is based on single structural break tests. ${ }^{1}$ In this context, we find Campa and Goldberg (2004) who perform two types of structural change tests on the pass-through elasticities. They first find that using the Chow test, exchange rate pass-through coefficients have been declined in both short-run and long-run for many OECD countries. They second show that based on the Andrews (1993), and Andrews and Ploberger (1994) tests, pass-through coefficients have declined in the short-run but not in the long-run. We also find the work of Bailliu and Eiji (2004) who investigate the question of whether a transition to a low-inflation environment induced by a shift in monetary policy results in a decline in the degree of pass-through of exchange rate movements to consumer prices.

Taylor's (2000) hypothesis stipulates that the low inflation environment in many industrialized countries has successfully reduced the degree of exchange rate pass-through to domestic prices. He argued that exchange rate pass-through is primarily a function of the persistence of exchange rate and price shocks, which tend to be reduced in an environment where inflation is low and monetary policy is more credible. Here, we show that the same phenomenon occurs for several developing countries. Focusing on Bolivia, Botswana, Chile, Colombia, Indonesia, Singapore, Uruguay and Venezuela we find import price pass-through declined during the 1990s and attribute this to a fall of inflation that was induced by a shift in monetary policy caused by exchange rate targeting or inflation targeting.

To that effect, we adopt two techniques, the multiple structural change approach of Bai and Perron (1998), and the cointegration tests allowing one break at unknown time proposed by Gregory and Hansen (1996). The use of these tests is motivated by the fact that on the one hand, the Bai and Perron (1998) approach allows identifying the inflation decline, and on the other hand, by using the Gregory and Hansen (1996) tests, we adopt a long-run approach; more precisely, we investigate for a possible exchange rate pass-through decline through a cointegration framework. In effect, by adopting this approach, we attempt to remedy a notable gap existing in several empirical approaches related to the pass-through, which ignore the long-run and substitute it by an ad hoc measure. This is due to the failure

\footnotetext{
${ }^{1}$ Note that in this paper, we use multiple structural change tests since the considered data series (see Figure 1) can present some breaks in their structure.
} 
to find evidence for cointegration from the data. ${ }^{2}$

This paper is structured as follows. Section 2 reviews the econometric techniques of Bai and Perron (1998), and Gregory and Hansen (1996), ${ }^{3}$ to investigate the inflation and exchange rate pass-through declines. Section 3 presents the adopted methodology, reports the obtained results and provides some economic explanations. The results indicate that the exchange rate pass-through into import prices declined in the 1990s in some developing countries, and that such declines are explained by inflation decreases. This is explained by the fact that the change in the monetary policy of these countries caused a shift to a low inflation environment, and hence an exchange rate pass-through drop. Section 4 concludes the paper.

\section{Econometric techniques}

We consider the following mean-shift model with $m$ breaks, $\left(T_{1}, \ldots, T_{m}\right):^{4}$

$$
y_{t}=\delta_{j}+u_{t}, \quad t=T_{j-1}+1, \ldots, T_{j},
$$

where $j=1, \ldots, m+1, T_{0}=0$ and $T_{m+1}=T$. $y_{t}$ is the observed dependent variable, $\delta_{j}$ are the regression coefficients with $\delta_{i} \neq \delta_{i+1}(1 \leq i \leq m)$, and $u_{t}$ is the error term. The estimation method developed in Bai and Perron (1998) is based on the ordinary least-squares (OLS) principle. It consists in estimating the regression coefficients $\delta_{j}$ and the break dates $\left(T_{1}, \ldots, T_{m}\right)$ under the condition that $T_{i}-T_{i-1} \geq[\varepsilon T]$, where $\varepsilon$ is an arbitrary small positive number and [.] denotes integer part of argument.

Bai and Perron (2003a) propose a test-based selection procedure to estimate the number of breaks. Indeed, they suggest to first look at the results of tests $U D \max F_{T}$ or $W D \max F_{T}{ }^{5}$ to see if at least one structural break exists. The number of breaks is then determined based upon a sequential examination of a test $\sup F_{T}(l+1 \mid l) .{ }^{6}$ We then choose $m$ break dates such that the test $\sup F_{T}(l+1 \mid l)$ is not significant for any $l \geq m$. The usefulness of this method is illustrated by some works such as Bai and Perron (2003a), and Jouini and Boutahar (2005).

We now introduce the cointegration approach of Gregory and Hansen (1996). Let the standard model of cointegration with no structural change;

$$
z_{t}=\mu+\theta^{\prime} x_{t}+\epsilon_{t}, \quad t=1, \ldots, T
$$

\footnotetext{
${ }^{2}$ Based on the micro-foundations of firms pricing, we consider exchange rate pass-through as an equilibrium profit maximizing strategy for firms (a long-run phenomenon) rather than a short-run phenomenon.

${ }^{3}$ To keep the paper short we only present the models, and the readers are referred to the corresponding authors for the expressions of the test statistics.

${ }^{4}$ This specification choice is motivated by the fact that a look at the inflation graphs (see Figure 1) suggests that they may be affected by structural breaks with potential mean-shifts.

${ }^{5}$ These tests allow testing the null hypothesis of no break versus an unknown number of changes given a maximum permitted number of breaks $M$ for $m$. At the $5 \%$ significance level, the asymptotic critical values of the tests $U D \max F_{T}$ and $W D \max F_{T}$ are respectively 8.88 and 9.91 (see Bai and Perron, 2003b).

${ }^{6}$ It tests the null hypothesis of $l$ breaks against the alternative that an additional break date exists. At the $5 \%$ significance level, the asymptotic critical values are $10.13(l=1), 11.14(l=2), 11.83(l=3)$ and 12.25 $(l=4)$ (see Bai and Perron, 2003b).
} 
where $z_{t}$ is real-valued, the $n$-vector $x_{t}$ is $I(1)$ and $\epsilon_{t}$ is $I(0)$. To take into account the fact that cointegration holds over some period of time and then shifts to a new long-run relationship, we consider the following one-break model:

$$
z_{t}=\mu_{1}+\mu_{2} \psi_{t \tau}+\theta_{1}^{\prime} x_{t}+\theta_{2}^{\prime} x_{t} \psi_{t \tau}+\epsilon_{t}, \quad t=1, \ldots, T
$$

where $^{7}$

$$
\psi_{t \tau}= \begin{cases}0, & \text { if } t \leq[\tau T], \\ 1, & \text { if } t>[\tau T],\end{cases}
$$

with $\tau \in(0,1)$ the timing of the break date. Gregory and Hansen (1996) test the null of no cointegration that (2) holds with $\epsilon_{t} \equiv I(1)$ against the alternative in model (3). To handle regime-shifts and based on the estimation by OLS of the model (3), the authors propose three cointegration test statistics $A D F^{*}, Z_{t}^{*}$ and $Z_{\alpha}^{*}{ }^{8}$

\section{Empirical methodology}

The main problem in empirical studies on developing countries is data availability. Because of the difficulty to find some variables such as the nominal and real effective exchange rates, the consumer price index and the import price, in particular on monthly or quarterly frequency, we only consider a sample of 8 developing countries, namely Bolivia, Botswana, Chile, Colombia, Indonesia, Singapore, Uruguay and Venezuela. The data are quarterly, span the period 1980:2-2003:4 (yielding 95 observations) and are obtained from International Financial Statistics. Based on the Taylor (2000) proposition that the low inflation environment can cause a low exchange rate pass-through, we first analyze the inflation decline in the developing countries by using the above-mentioned test-based selection procedure; and we then investigate the decline of exchange rate pass-through by using the cointegration approach. Our empirical methodology consists in comparing the break dates detected for the inflation series and the exchange rate pass-through equation especially those identified near the 1990s. Once we have determined the dates, we investigate the sign of their coefficient and see whether it corresponds to a decline of both inflation and pass-through.

\subsection{Inflation environment}

In order to attribute the low exchange rate pass-through to a lower-inflation environment as in Taylor (2000), one needs to document the extent to which inflation did indeed decline in our sample. From Figure 1, the structural change procedure ${ }^{9}$ shows that the aggregate inflation $^{10}$

\footnotetext{
${ }^{7}$ We consider the case where the change affects the parameters $\mu$ and $\theta$.

${ }^{8}$ At the $5 \%$ significance level, the asymptotic critical values of the tests $A D F^{*}, Z_{t}^{*}$ and $Z_{\alpha}^{*}$ are respectively $-6.41,-6.41$ and -78.52 (see Gregory and Hansen, 1996).

${ }^{9}$ Note that this procedure is applied for $M=5$ and $\varepsilon=0.15$.

${ }^{10}$ The aggregate inflation is calculated as the percentage change of the aggregate CPI (calculated by 136 developing countries by the International Monetary Fund, IMF) expressed in logarithm.
} 
presents two breaks (1983:3 and 1993:2) and that for the individual inflation series ${ }^{11}$, the bulk of the break dates occurs in the middle of the 1980s and during the 1990s. ${ }^{12}$ The selected breaks for the aggregate inflation correspond to a decline since the estimates of the coefficients are $\hat{\delta}_{1}=0.0084, \hat{\delta}_{2}=0.0041$ and $\hat{\delta}_{3}=0.0017 .{ }^{13}$ The first fall in inflation (1983:3) is due to a change in the monetary policy paradigm. Under the influence of Milton Friedman, the reduction of inflation via inflation targeting becomes a priority for the United States from 1981 onwards. Given the important degree of the dollarisation of many developing countries, the decline in the US inflation rate caused aggregate inflation in developing countries to decline as well. The second drop in inflation (1993:2) can be explained by a global economic recession starting at the beginning of the 1990s, which caused world demand and hence inflation to drop. Another possible explanation for this inflation decline can be attributed to a change in monetary policy in some developing countries. For the individual series, the results given in Table 1 indicate that the inflation declines in most dates. This can be seen by the estimated value of $\delta_{i}$ being greater than that of $\delta_{i+1}$. In this context, in order to reduce their inflation rate, some developing countries adopted different monetary policies such as exchange rate targeting and/or inflation targeting. Table 2 provides further details about the monetary shift in these countries.

\subsection{Pass-through decline}

In this paper, the equation used to estimate the degree of the exchange rate pass-through into import prices is similar to the equation found in the literature in this area (see, Hooper and Mann, 1989; Goldberg and Knetter, 1997; Campa and Goldberg, 2003; and Barhoumi 2005, 2006). We consider that exchange rate pass-through into import price is determined by a combination of nominal effective exchange rate, the price of the competing domestic product, the exporters costs and domestic demand conditions. Additionally, we adopt the assumption of imperfectly competitive market structures, concentrate on the micro-foundations of firms' pricing and regard exchange rate pass-through as an equilibrium profit maximizing strategy for firms (a long-run phenomenon) rather than a short-run phenomenon caused by the contractual stickiness of prices. The exchange rate pass-through equation is the following: ${ }^{14}$

$$
p m_{t}=\mu+\beta_{1} e_{t}+\beta_{2} c_{t}+\beta_{3} p_{t}+\beta_{4} I_{t}
$$

where ${ }^{15} \mathrm{pm}_{t}$ is the import unit value in domestic currency (index numbers $\left.(1995=100)\right), e_{t}$ is the nominal effective exchange rate from Information Notion system (exchange rate index $1995=100), p_{t}$ is the Producer Price Index (PPI) (index numbers $(1995=100)$ ), $I_{t}$ is the

\footnotetext{
${ }^{11}$ We analyze the inflation behavior for each country by using the headline inflation calculated as the percentage change of the headline CPI expressed in logarithm.

${ }^{12}$ The graph of Indonesia's inflation is not reported since it does not present breaks in its structure.

${ }^{13}$ Note that the coefficient $\delta_{j}$ measures the average inflation in the regime $j$, and so a decline in the estimate implies a decline in the average rate of inflation.

${ }^{14}$ Note that we have tested for stationarity by using the ADF tests, which have argued unanimously on the order of integration to be 1 .

${ }^{15}$ Note that the coefficient $\beta_{1}$ is the long-run exchange rate pass-through.
} 
Industrial Price Index (IPI) (INDUST PRODUCTION, SEAS. ADJ) and $c_{t}$ is the marginal cost of production of foreign firm calculated as follows. Let

$$
C_{t}=Q_{t} \times \frac{\widetilde{P}_{t}}{E_{t}}
$$

where $E_{t}$ is the nominal effective exchange rate, $\widetilde{P}_{t}$ is the wholesale price index (due to data availability for some countries, we use the Consumer Price Index) and $Q_{t}$ is the real effective exchange rate (exchange rate index 1995 $=100$, based on real consumer price, index $1995=100$ ). Taking the logarithm of each variable, we obtain the following expression:

$$
c_{t}=q_{t}-e_{t}+\widetilde{p}_{t}
$$

In order to verify the Taylor (2000) proposition, we apply the above cointegration approach to the long-run exchange rate pass-through relationship (5) by considering the case where all the coefficients change over time as shown by the model (3). By inspecting the results of Table 3, note that except for Colombia and Venezuela, we reject the null of no cointegration for the other countries. Besides, the associated break dates are between the middle of the 1980s and during the 1990s as for the individual inflation series (Figure 1). We now investigate whether the observed inflation decreases (Table 1) are associated with a decline in the pass-through coefficient in the 1990s. Indeed, the results presented in Table 3 confirm this fact for the countries which present a break date except for Singapore. Now, we turn to give some explanations to this exchange rate pass-through decline. As mentioned previously, the exchange rate pass-through drop can be explained by a stable inflation environment due to a change in the monetary policy (Table 2).

In the following, we provide economic explanations for the pass-through decline in the different countries.

- For Bolivia, inflation declined two times (1987 and 1996) and was accompanied by a significant fall of the pass-through coefficient in 1989 ( $A D F^{*}$ test statistic) or $1990\left(Z_{t}^{*}\right.$ test statistic). The inflation decrease in Bolivia is explained by the adoption of a New Economic Policy, namely the ESAF arrangement in 1988.

- Botswana's inflation fell early 1996. This fall was accompanied by a significant exchange rate pass-through decline in 1998. This corresponds to the fact that Botswana adopted the Exchange Rate Targeting in June 1994.

- Inflation in Chile declined two times (1991 and 1995), leading to a significant passthrough decline in the middle of 1994. In September 1990, the Central Bank of Chile decided to announce an inflation target for the year 1991 after the oil price shock due to the 1990 Gulf War and expansionary policies in 1989 causing high inflation rates.

- For Indonesia, despite the fact that the structural break approach does not indicate an inflation decline, we show that the exchange rate pass-through decline occurred in 1999:1. 
- For Singapore, despite the fact that we find two inflation falls (1984 and 1997), we do not observe a decline in the pass-through.

- Uruguay's inflation decreased two times (1992 and 1996); these inflation declines are due to exchange rate regime change. Indeed, Uruguay shifted to a floating exchange rate in 1985 and at the end of the 1980s, Uruguay adopted an exchange rate target (Adjustable Peg/Exchange Rate Band). Hence, at the beginning of the 1990s the exchange rate pass-through declined in Uruguay.

Note that for some countries, we show that pass-through decline occurred before the inflation decline. We can attribute this configuration to the fact that if the disinflation policy is credible, the pass-through decline can intervene before the reduction of the inflation. In addition, the increase of the competition at the national level can lead, at the same moment, to a decline of the prices: a low inflation during several periods if the process is gradual and a decline of the pass-through, without that the one precedes the other one. In addition, Frankel et al. (2005) stipulate that the exchange rate pass-through decline can be explained by changes in the monetary environment. Real wages also work to reduce passthrough to competitors' prices and the CPI, confirming the hypothesized role of distribution and retail costs in pricing to market. The decline in the pass-through coefficient in some developing countries is attributed to the Balassa-Samuelson-Baumol effect which caused rising distribution costs.

\section{Conclusion}

Using quarterly data for 8 developing countries over the period 1980-2003, we find evidence that exchange rate pass-through into import prices declined in the 1990s in some countries. Our empirical findings give support to the Taylor (2000) proposition which stipulates that the low inflation environment in the 1990s has caused a low exchange rate pass-through. Indeed, we show that such pass-through declines in the considered countries are associated with inflation decreases in the period stretching from the 1980s to the 1990s. This is explained by the fact that the change in the monetary policy regimes of these countries caused a shift to a low inflation environment, and hence an exchange rate pass-through decline.

These results have important consequences in terms of policy implications for developing countries. First, a decline in the pass-through to consumer prices could influence central bankers' forecasts of the future path of inflation, a key element in the conduct of monetary policy. Second, if import prices are less responsive to movements in the exchange rate, this could lead to a dampening of "expenditure-switching" effects. These refer to the change in the composition of demand resulting from a change in relative international prices induced by movements in the nominal exchange rate. Finally, a decline in exchange rate pass-through also has important implications for the international transmission of shocks. According to Betts and Devereux (2000), when pass-through is complete, monetary policy produces a negative co-movement of output across countries. 

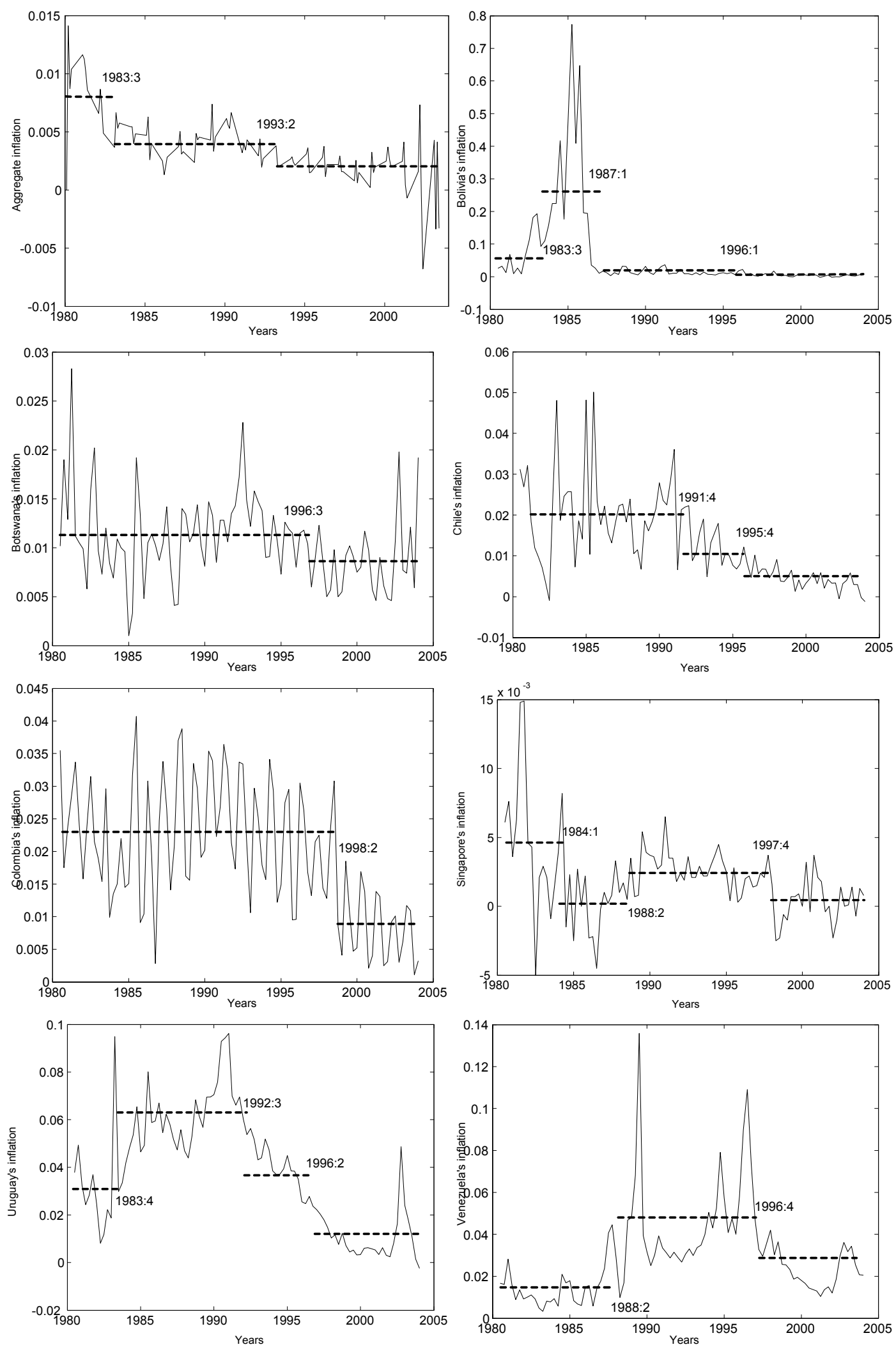

Figure 1. Graphs of the inflation series 
Table 1. Tests for breaks in inflation series

\begin{tabular}{|c|c|c|c|c|c|c|c|}
\hline \multirow[b]{2}{*}{ Country } & \multicolumn{3}{|c|}{ Break dates } & \multicolumn{4}{|c|}{ "Coefficients estimates } \\
\hline & $\overline{\hat{T}_{1}}$ & 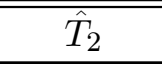 & 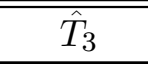 & $\overline{\hat{\delta}_{1}}$ & $\overline{\hat{\delta}_{2}}$ & $\overline{\hat{\delta}_{3}}$ & $\overline{\hat{\delta}_{4}}$ \\
\hline Bolivia & 1983:3 & $1987: 1^{+}$ & 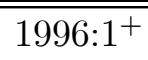 & "0.0781 & 0.2732 & 0.0137 & 0.0039 \\
\hline Botswana & $1996: 3^{+}$ & & & 0.0115 & 0.0086 & & \\
\hline Chile & $1991: 4^{+}$ & $1995: 4^{+}$ & & 0.0206 & 0.0111 & 0.0041 & \\
\hline Colombia & $1998: 2^{+}$ & & & 0.0229 & 0.0080 & & \\
\hline Indonesia & \multicolumn{7}{|c|}{ No break } \\
\hline Singapore & $1984: 1^{+}$ & 1988:2 & $1997: 4^{+}$ & 0.0048 & 0.0001 & 0.0026 & 0.0003 \\
\hline Uruguay & 1983:4 & $1992: 3^{+}$ & $1996: 2^{+}$ & 0.0329 & 0.0624 & 0.0382 & 0.0109 \\
\hline Venezuela & 1988:2 & $1996: 4^{+}$ & & 0.0148 & 0.0481 & 0.0237 & \\
\hline
\end{tabular}

Note: ${ }^{+}$In these dates, there is an inflation decline.

Table 2. Identified changes in the monetary policy

\begin{tabular}{l|l|l}
\hline \hline Country & Break date & Monetary policy change \\
\hline \hline Bolivia & $1989: 3$ and 1990:4 & Exchange rate targeting \\
\hline Botswana & $1998: 3$ & Exchange rate targeting \\
\hline Chile & $1994: 2$ & Inflation targeting \\
\hline Uruguay & $1990: 4$ and 1991:1 & Exchange rate targeting \\
\hline
\end{tabular}

Table 3. Tests for breaks in pass-through estimates

\begin{tabular}{|c|c|c|c|c|c|c|}
\hline & \multicolumn{2}{|c|}{$A D F^{*}$} & \multicolumn{2}{|c|}{$Z_{t}^{*}$} & \multicolumn{2}{|c|}{$Z_{\alpha}^{*}$} \\
\hline Country & $\hat{T}_{1}$ & $\beta_{1}$ & $\hat{T}_{1}$ & $\beta_{1}$ & $\hat{T}_{1}$ & $\beta_{1}$ \\
\hline Bolivia & $1989: 3^{+}$ & $\begin{array}{l}-0.380 \\
-0.392\end{array}$ & $1990: 4^{+}$ & $\begin{array}{r}0.387 \\
-0.285\end{array}$ & $\mathrm{No}$ & reak \\
\hline Botswana & No b & reak & $1998: 3^{+}$ & $\begin{array}{l}0.902 \\
0.357 \\
\end{array}$ & $1998: 3^{+}$ & $\begin{array}{l}0.902 \\
0.357 \\
\end{array}$ \\
\hline Chile & $1994: 2^{+}$ & $\begin{array}{l}-0.855 \\
-0.937 \\
\end{array}$ & $1994: 2^{+}$ & $\begin{array}{l}-0.855 \\
-0.937 \\
\end{array}$ & $\mathrm{No}$ & ceak \\
\hline Colombia & No b & reak & Nol & ceak & No & reak \\
\hline Indonesia & $1999: 1^{+}$ & $\begin{array}{l}-0.381 \\
-0.971\end{array}$ & 1998:4 & $\begin{array}{r}-0.951 \\
0.985\end{array}$ & No & eak \\
\hline Singapore & No b & reak & 1986:1 & $\begin{array}{l}-0.318 \\
-0.059\end{array}$ & $\mathrm{No}$ & reak \\
\hline Uruguay & $1991: 1^{+}$ & $\begin{array}{r}0.829 \\
-0.170 \\
\end{array}$ & $1990: 4^{+}$ & $\begin{array}{r}0.854 \\
-0.162 \\
\end{array}$ & $1990: 4^{+}$ & $\begin{array}{r}0.854 \\
-0.162\end{array}$ \\
\hline Venezuela & No b & reak & Nol & ceak & $\mathrm{No}$ & eak \\
\hline
\end{tabular}

Notes: ${ }^{+}$denotes a significant exchange rate pass-through decline.

$\beta_{1}$ is the value of the pass-through coefficient. Top: the value before the break date, and bottom: the value after the break date. 


\section{References}

[1] Andrews, D.W.K. (1993) "Tests for parameter instability and structural change with unknown point", Econometrica 61, 821-856.

[2] Andrews, D.W.K., and W. Ploberger (1994) "Optimal tests when a nuisance parameter is present only under the alternative", Econometrica 62, 1381-1414.

[3] Bai, J., and P. Perron (1998) "Estimating and testing linear models with multiple structural changes", Econometrica 66, 47-78.

[4] Bai, J., and P. Perron (2003a) "Computation and analysis of multiple structural change models", Journal of Applied Econometrics 18, 1-22.

[5] Bai, J., and P. Perron (2003b) "Critical values for multiple structural change tests", Econometrics Journal 1, 1-7.

[6] Barhoumi, K. (2005) "Exchange rate pass-through into import prices in developing countries: an empirical investigation", Economics Bulletin 3, 1-14.

[7] Barhoumi, K. (2006) "Differences in long run exchange rate pass-through into import prices in developing countries: an empirical investigation", Economic Modelling 23, 926951.

[8] Betts, C., and M.B. Devereux (2000) "Exchange rate dynamics in a model of pricing-tomarket", Journal of International Economics 50, 214-244.

[9] Campa, J.M., and L.S. Goldberg (2003) "Exchange rate pass-through into import prices: a macro or micro phenomenon?" Federal Reserve Bank of New York, mimeo.

[10] Campa, J.M., and L.S. Goldberg (2004) "Exchange rate pass-through into import prices", Discussion Paper $n^{\circ}$ 4391, Centre for Economic Policy Research.

[11] Devereux, M., and J. Yetman (2001) "Predetermined prices and the persistent effects of money on output", Working Paper 01-13, Bank of Canada.

[12] Frankel, J., Parsley, D., and S.J. Wei (2005) "Slow pass-through around the world: a new import for developing countries?" NBER Working Paper $n^{\circ} 11199$.

[13] Gagnon, J., and J. Ihrig (2001) "Monetary policy and exchange rate pass-through", International Finance Discussion Paper $n^{\circ}$ 704, Board of Governors of the Federal Reserve System, Washington DC.

[14] Goldberg, P.K., and M. Knetter (1997) "Goods prices and exchange rate: what have we learned?" Journal of Economic Literature 35, 1243-1272.

[15] Gregory, A., and B.E. Hansen (1996) "Residual-based tests for cointegration in models with regime shifts", Journal of Econometrics 70, 99-126. 
[16] Hooper, P., and C.L. Mann (1989) "Exchange rate pass-through in the 1980s: the case of US imports of manufactures", Brookings Papers of Economic Activity, 1.

[17] Jouini, J., and M. Boutahar (2005) "Evidence on structural changes in US time series", Economic Modelling 22, 391-422.

[18] Phillips, P.C.B. (1987) "Time series regression with a unit root", Econometrica 55, 277-301.

[19] Taylor, J. (2000) "Low inflation, pass-through, and the pricing power of firms", European Economic Review 44, 1389-1408. 